\title{
Formal Analysis of an Agent Support Model for Behaviour Change Intervention
}

\author{
Ojeniyi Adegoke ${ }^{\# 1}$, Azizi Ab Aziz ${ }^{\# 2}$, Yuhanis Yusof ${ }^{\# 2}$ \\ Human-Centred Computing Research Laboratory (HCC), School of Computing (SOC), \\ Universiti Utara Malaysia (UUM), 0610 Sintok, Malaysia \\ E-mail: ${ }^{1}$ go4oje@yahoo.com, ${ }^{2}\{$ aziziaziz,yuhanis\}@uum.edu.my
}

\begin{abstract}
Agent applications have been widely used in behaviour change intervention nowadays. This is due to the four features of agents: proactive, reactivity, social ability and autonomy. However, psychological reactance is one of the major limiting causes of agent interventions. Although, many studies have investigated into both psychological reactance and behaviour change nevertheless how reactive intervention can be supported to obtain an improved behaviour change intervention is still lacking in most previous studies. Therefore, this paper describes the formal analysis of agent support model for behaviour change intervention. The analysis made use of two widely accepted approaches in agent formal evaluation namely mathematical analysis and automated verification. The mathematical analysis examined the correctness of the formal model representation and formalization that aimed to ensure that all syntax and semantic representations used in the formal model is consistent. The mathematical analysis used equilibrium property to explore the formal model consistency. Likewise, automated verification depicts the checking of the model properties against its specifications and theoretical traces. The automated verification used Temporal Trace Language (TTL), which verifies the model properties and states against generated traces. The paper presents an agent support model that allows building agent-based software and applications that deflect psychological reactance and enhance an improved behavioural change intervention.
\end{abstract}

Keywords - behaviour change intervention; psychological reactance; agent-based simulation; agent-based model; support model

\section{INTRODUCTION}

Agent intervention embroils re-modification or prevention of undesirable behaviour using systematically planned operation in a process or system [1], [2]. It consists of intended, strategic and targeted implemented procedures based on communicable and social medium to achieve behaviour modification of an individual, a group or a population [3]. This involves scheme and procedure based on behavioural principles in order to achieve the targeted behavioural outcome. The target behaviour can be in health, politics, mental and physical contexts. The sustainability of this behaviour change intervention is of significance and value to agent-based system community [4], [5]. However, many behaviour change interventions were not able to achieve the target objective and psychological reactance has been identified as the reason for these unsuccessful behavioural change interventions [6], [7], [8].

Psychological reactance occurs when the free behaviour of an individual infringed by persuasive intention to cause behavioural change and it usually manifests in forms of anger, irritation, frustration and refusal of target behaviour or action [7], [9]. This is as a result that the individual freedom to behave freely infringed during the behaviour change intervention, which made it impossible to act autonomously in order to decide between the multiple possibilities of behaviour available. Thus, psychological reactance is an experience that occurs whenever a free behaviour is restricted. Reactance is an aversive affective reaction in response to regulations or impositions that impinge on freedom and autonomy.

Furthermore, reactance occurs during threatening influence, which usually manifests in forms of unfavourable emotion and cognitive responses [10], [11]. This unfavourable emotion and cognition directly trigger certain behavioural determinants that attempt to restore the perceived threatened freedom [12]. Consequently, one can infer that there are two assumptions involved in reactance concept. Firstly, the audience has a desire for freedom. Secondly, the attempt of agent intervention usually threatens this intrinsic desire. When this intrinsic desire is threatened, it triggers an arousal state that operates to protect the further loss of freedom. The triggered arousal state is to recover the loss of freedom or its reduction further. This phenomenon depicts the resistance in behaviour change and leads to failure of behavioural change interventions. Thus, in order to 
design an effective agent intervention system, it is necessary to understand the underlying mechanisms of psychological reactance with behaviour change and to influence these mechanisms to establish the desired behaviour.

Although, there are studies in the vast literature that examined psychological reactance and behaviour change interventions, such as [13], [14], [15], [16], [17], [18] and [19]. However, none of these previous studies explored formal analysis to understand explicitly how to support psychological reactance to obtain an improved behaviour change intervention. Hence, a formal model is desirable for this study because it depicts agent's mental stance in behaviour change processes.

Agent-based model (ABM) is one of a class of computational models (formal models) for simulating the actions and interactions of autonomous agents (both individual and collective entities) with a view to assess their effects on their behaviour as a whole [20], [21]. Its theoretical based concept used to study and comprehend behaviours of complex phenomena by means of model simulations [22]. The results of model simulations help researchers make predictions about what will happen in real life scenario in response to different behaviour changing conditions [23]. Thus, ABM provides explicitly and comprehends how agent achieves successful behavioural change intervention process. This paper computerizes existing psychology theories of behaviour change and psychological reactance to comprehend agent's behavioural factor interactions. Therefore, this study provides a formal analysis of agent model as presented in Fogg's study [3]. The formal analysis is conducted using two approaches namely, mathematical analysis and automated verification in order to evaluate the proposed model.

\section{MATERIAL AND METHOD}

The proposed agent support model utilized existing psychology theories that describe related factors (cognitive and behavioural) and phenomena in psychological reactance and behaviour change. The model employed agent-based simulation methodology based on the eight theories namely Fogg's Behavioural Model (FBM) [24], Relapse Prevention Model (RPM) [25], Trans-Theoretical Model (TM) [26], Self-Efficacy Theory (SET) [27], Self-Regulation Theory (SRT) [28], Theory of Reasoned Action (TRA) [29], Theory of Planned Behaviour (TPB) [30] and Health Belief Model (HBM) [31]. Fig. 1 illustrates the agent support model.

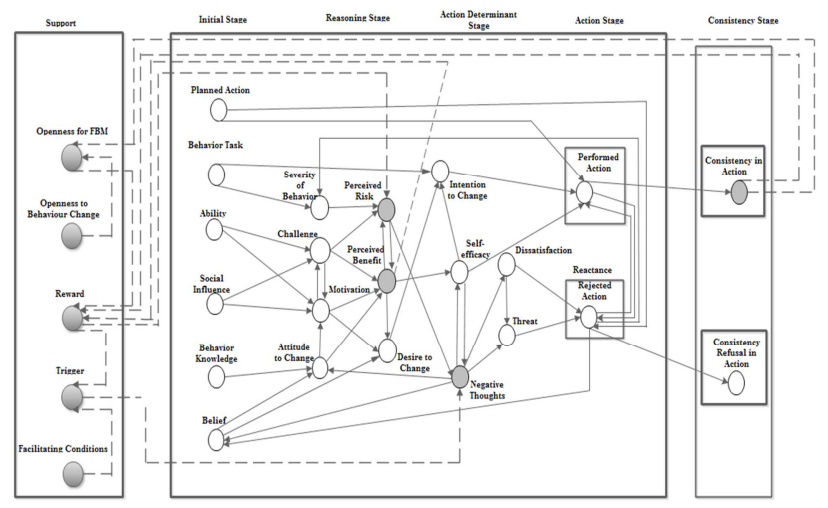

Fig. 1 Agent support model for behaviour change
The arrows in Fig. 1 denotes causal dependencies of interrelated factors. The formalization of the model was specified using differential equation. The designed model depicts that Openness to FBM $(* O f)$ is high when any of consistency in action $(\mathrm{Ca})$ or openness to behaviour $(* \mathrm{Ob})$ is high which was formalized as shown in equation (1) and a similar concept was used in Equation (2) and (3).

$$
\begin{gathered}
* O f(\mathrm{t})=\beta \cdot C a(\mathrm{t})+\left[\left(1-\beta_{f}\right) \cdot O b(\mathrm{t})\right] \\
S b(\mathrm{t})=B a(\mathrm{t})[1-(1-A r(\mathrm{t}))] \\
S e(\mathrm{t})=P b(\mathrm{t}) \cdot[1-\mathrm{Ng}(\mathrm{t})]
\end{gathered}
$$

Challenge $(C g)$ is perceived obstacle or impediment to target behaviour. Based on the model, challenge $(\mathrm{Cg})$ is high when any two of ability $(A b)$, social influence $(\mathrm{Si})$ and motivation $(M v)$ are high. This principle is employ to formalize the concept of challenge $(C g)$ as shown in equation (4). Similar principle is employ to formalize perceived benefit $(P b)$, performed action $(P c)$ and action reject $(A r)$ as presented in Equations (5), (6) and (7) respectively.

$$
\begin{gathered}
C g(\mathrm{t})=\mathrm{w}_{\mathrm{c} 1} \cdot A b(\mathrm{t})+\mathrm{w}_{\mathrm{c} 2} \cdot \operatorname{Si}(\mathrm{t})+\mathrm{w}_{\mathrm{c} 3} \cdot M v(\mathrm{t}) \\
P b(\mathrm{t})=\left[\mathrm{w}_{\mathrm{pb} 1} \cdot A c(\mathrm{t})+\mathrm{w}_{\mathrm{pb} 2} \cdot M v(\mathrm{t})+\mathrm{w}_{\mathrm{pb} 3} \cdot C g(\mathrm{t})\right] \cdot(1-P r(\mathrm{t})) \\
P c(t)=\left[\mathrm{w}_{\mathrm{Pc} 1} \cdot P a(t)+\mathrm{w}_{\mathrm{Pc} 2} \cdot I c(t)+\mathrm{w}_{\mathrm{Pc} 3} \cdot \operatorname{Se}(t)\right] \cdot(1-A r(t)) \\
A r(t)=\left[\mathrm{w}_{\mathrm{Ar} 1} \cdot D f(t)+\mathrm{w}_{\mathrm{Ar} 2} \cdot \operatorname{Hr}(t)+\mathrm{w}_{\mathrm{Ar} 3} \cdot \operatorname{Pa}(t)\right] \cdot(1-(P c(t))
\end{gathered}
$$

Where $\sum_{j=3}^{1} W c j=1, \quad \sum_{j=3}^{1} W p b j=1, \quad \sum_{j=3}^{1} \mathrm{Wpcj}=$ 1 and $\sum_{j=3}^{1}$ Warj $=1$, and $\mathrm{w}_{\mathrm{c} 1}, \mathrm{w}_{\mathrm{c} 2}, \mathrm{w}_{\mathrm{c} 3}, \mathrm{w}_{\mathrm{pb} 1}, \mathrm{w}_{\mathrm{pb} 2}, \mathrm{w}_{\mathrm{pb} 3}, \mathrm{w}_{\mathrm{Pc} 1}$, $\mathrm{w}_{\mathrm{Pc} 2}, \mathrm{w}_{\mathrm{Pc} 3}, \mathrm{w}_{\mathrm{Ar} 1}, \mathrm{w}_{\mathrm{Ar} 2}$ and $\mathrm{w}_{\mathrm{Ar} 3}$ are the weight of the equations.

Motivation $(M v)$ is the simulative drive and intrinsic interest in performing the behaviour. Based on the designed model, the motivational $(M v)$ level is low if attitude to change $(A c)$, ability $(A b)$, challenge $(C g)$ and social influence $(\mathrm{Si})$ are low (as presented in equation (8)). Similar concept is employ to formalize equations (9), (10), (11), (12), (13), (14), (15) and (16).

$$
\begin{gathered}
M v(t)=\sigma\left(\mathrm{w}_{\mathrm{m} 1} A b(t)+\mathrm{w}_{\mathrm{m} 2} \cdot S i(t)+\mathrm{w}_{\mathrm{m} 1} C g(t)\right)+(1-\sigma)(A c(t) \\
A c(t)=[\gamma * B k(t)+(1-\gamma) * B f(t)][1-N g(t)] \\
\left.* P r(t)=[1-\mathrm{Rd}(\mathrm{t})] \cdot[\operatorname{Sb}(t)] *\left[1-\rho^{*} C g(t)+(1-\rho) * P b(t)\right)\right] \\
* T g(\mathrm{t})=\mu \cdot * F c(\mathrm{t})+[(1-\mu) \cdot R d(\mathrm{t})] \\
* R d(\mathrm{t})=P b(\mathrm{t}) \cdot[\overline{\mathrm{w}} \cdot C a(\mathrm{t})+(1-\overline{\mathrm{w}}) \cdot * O f(\mathrm{t})] \\
D c(t)=B f(t) \cdot[\eta \cdot M v(t)+(1-\eta) \cdot P b(t)] \\
I c(\mathrm{t})=\operatorname{Dc}(\mathrm{t}) *\left[v^{*} \operatorname{Se}(\mathrm{t})+(1-v) * B a(\mathrm{t})\right] \\
* N g(\mathrm{t})=\psi \cdot \operatorname{Pr}(\mathrm{t})+[(1-\psi) \cdot \operatorname{Se}(\mathrm{t})][1-\mathrm{Tg}(\mathrm{t})]
\end{gathered}
$$




$$
H r(\mathrm{t})=\phi * D f(\mathrm{t})+[(1-\phi) * N g(\mathrm{t})]
$$

Likewise, dissatisfaction $(D f)$ is the negative unpleasant feeling, negative expectation and negative reaction from behaviour. The concept relates to negative thought $(\mathrm{Ng})$, as formalized in equation (17). Consistency in action $(\mathrm{Ca})$ and consistency refusal in action $(\mathrm{Cr})$ formalization used similar procedure as presented in equations (18) and (19).

$$
\begin{aligned}
& D f(t+\Delta \mathrm{t})=D f(t)+\lambda *[N g(t)-D f(t)] *(1-D f(t)) *(D f(t) * \Delta \mathrm{t}) \\
& C a(t+\Delta \mathrm{t})=C a(t)+\zeta *[P c(t)-C a(t)] *(1-C a(t)) *(C a(t) * \Delta \mathrm{t}) \\
& C r(t+\Delta \mathrm{t})=C r(t)+\varphi^{*}[\operatorname{Ar}(t)-C r(t)] *(1-C r(t)) *(C r(t) * \Delta \mathrm{t})
\end{aligned}
$$

The $\sigma, \gamma, \rho, \mu, v, \lambda, \eta, \psi, \phi, \bar{w}, \zeta$ and $\varphi$ are regulating parameters while $\Delta t$ is the change in time. Detailed description and explanation of this model is presented in study [23] while, the next section explored the model verification which is the main aim of this study.

\section{A. Simulation}

The formal model (as presented in equations (1) to (19) and illustrated in Fig. 1) is analysed by implementing the model in the numerical Matlab simulation environment using three case conditions as shown in Table 1.

TABLE I

SIMULATION CASE CONDITION

\begin{tabular}{|c|c|c|c|}
\hline Concept & \multicolumn{3}{|c|}{ Case Condition } \\
\hline$P a$ & 0.2 & 0.9 & 0.2 \\
Agent & $\begin{array}{c}\text { Belief Deficient } \\
\text { Agent }\end{array}$ & $\begin{array}{c}\text { Task Challenging } \\
\text { Agent }\end{array}$ \\
\hline$B a$ & 0.9 & 0.2 & 0.9 \\
\hline$A b$ & 0.2 & 0.9 & 0.2 \\
\hline$S i$ & 0.2 & 0.9 & 0.9 \\
\hline$B k$ & 0.2 & 0.2 & 0.9 \\
\hline$B f$ & 0.2 & 0.2 & 0.9 \\
\hline \multicolumn{5}{|c|}{ Support } \\
\hline$P a$ & 0.9 & 0.9 & 0.9 \\
\hline$F c$ & 0.9 & 0.9 & 0.9 \\
\hline$O b$ & 0.9 & 0.9 & 0.9 \\
\hline
\end{tabular}

For instance, Whereas, On the other hand, all the three case conditions are supported by high Planned Action $(\mathrm{Pa})$, Facilitation Conditions $(F c)$ and Openness to Behaviour $(\mathrm{Ob})$.

The simulation results display the fundamental uniqueness of each case condition. The obtained simulation traces reflect that the model accounts for behavioural phenomena found in psychology and sociology. For instance, uninspiring agent defines an agent attribution with high Behavioural task $(B a)$ and low Planned action $(\mathrm{Pa})$, Ability $(A b)$, Society influence $(S i)$, Behavioural knowledge $(B k)$ and Belief $(B f)$. The obtained traces for an uninspiring agent without support reflects that this agent experiences psychological reactance as represented in Fig. 2a.

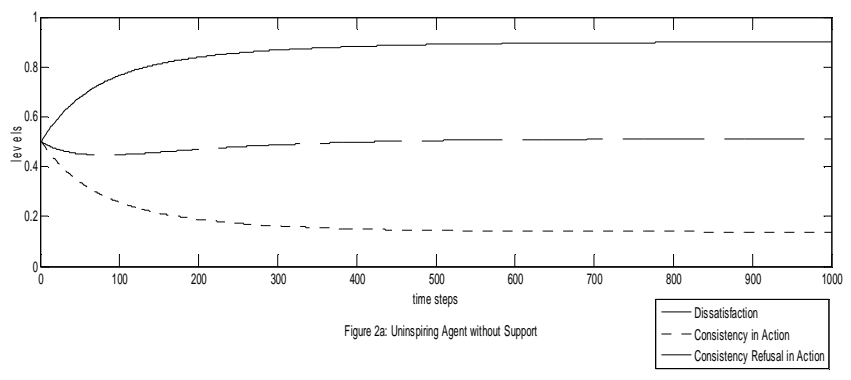

Fig. 2a Uninspiring Case Condition without Support

Fig. 2a shows that when this attribution is without support, there will be an increased dissatisfaction that follows by consistency refusal in the target action with a reduced consistency in target action. This implies that agent with such attribution will be characterized with high reactance because of the increased dissatisfaction and consistency refusal in action which will make consistency in target action or behaviour to be impossible.

On the other hand, the introduction of support to this uninspiring agent at time step 1000 gives simulation traces as presented in Fig. 2b. The introduced support causes a sharp increment in consistency in action and reduction in both dissatisfaction and consistency refusal in action.

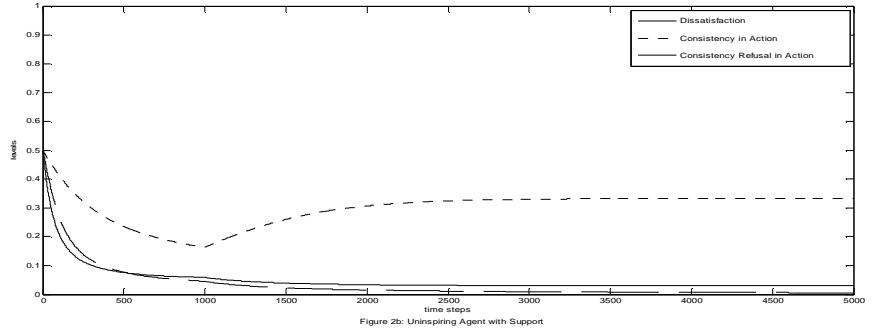

Fig. 2b Uninspiring case condition with support

Similarly, Belief deficient agent attribution depicts an agent with low belief, behavioural knowledge, planned action and high ability, society influence, behavioural task. When this attribution is without support, the agent experience psychological reactance as represented in Fig. 3a

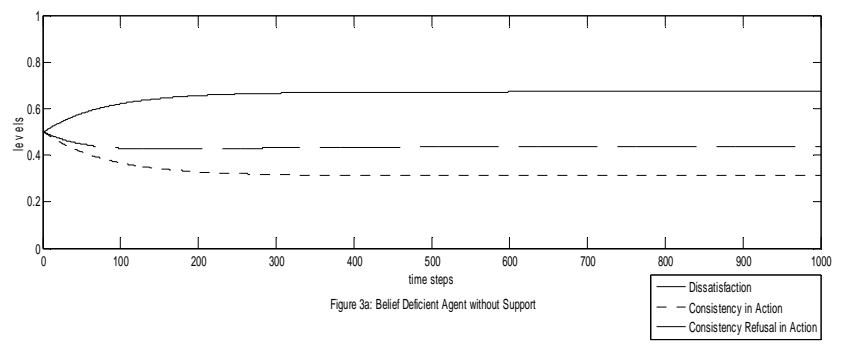

Fig. 3a Belief deficient case condition without support

This implies this agent is characterizes with high reactance because of high dissatisfaction and will make the agent unable to perform target behaviour. However, the introduction of the support at time step 1000 gave a different situation whereas there is a sharp increment in consistency in action and reduction in both dissatisfaction and consistency refusal in action shown in Fig. 3b. 


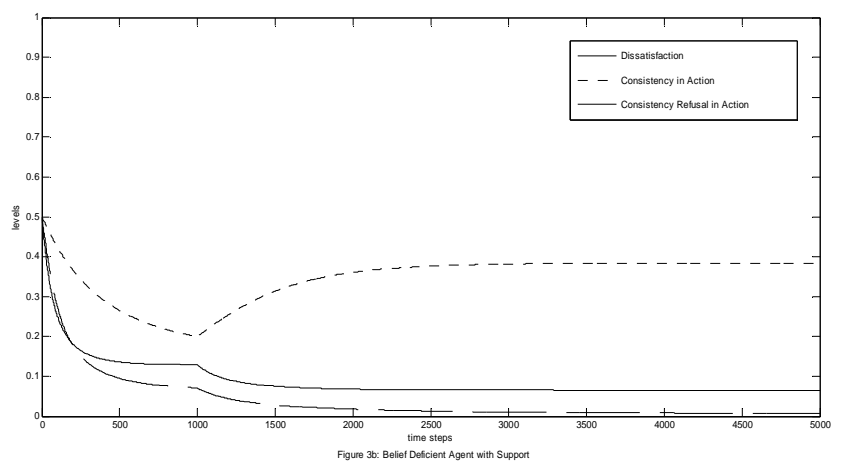

Fig. 3b Belief deficient case condition with support

The above figure depicts the leading of consistency in action with a very wide range margin whereas dissatisfaction is constant at 0.05 and consistency refusal in action was tending to zero. This implies that when belief deficient agent attribution with adequate support will result to reduced psychological reactance, which will make consistency in action or behaviour to be possible.

In summary, these case conditions simulation traces depict that with adequate support reactance attribution agents will generate an improved behaviour or action. Hence, this paper gives a comprehensive understanding on how psychological reactance agents are supported to obtain improved behaviour change outcome as seen from Fig. 2b and Fig. 3b. Many studies such as [10], [12], [32], [33] suggested that psychological reactance defect behaviour change which was identified as a major cause of unsuccessful behaviour change intervention. However, most of these studies did not explicitly explain how psychological reactance defect behaviour.

Although studies like [3], [4], [34] explained the processes involved in an improved behaviour change, however, these studies did not explicitly explain how psychological reactance can be supported to have an improved behaviour change outcome which will lead to successful behaviour change interventions. Therefore, this paper has provided a computational model that can explicitly explain how psychological reactance will be support to obtain an improved behaviour change intervention.

\section{RESULT AND DISCUSSION}

This paper made use of two methods in order to verify the model, which includes mathematical analysis and automated verification. These two methods implemented to verify unique properties of the proposed model [35]. The mathematical analysis conducted to verify the structural and theoretical correctness of the model, which implement using equillbria analysis. The equilibria property describes the situation to obtain stability condition. It means if the dynamics of a system is described by a differential equation, then equilibria can be estimated by setting a derivative (or all derivatives) to zero. On the other hand, the obtained automated verification uses Temporal Trace Language (TTL). TTL make use of logical verification, which analyzes the obtained traces against theoretical implication. This specification language and verification tool allow the deep interpretation on further verification using both qualitative and quantitative methods under analysis [36]. In order to verify whether the model indeed generates results that are in adherence with the literature, a set of properties from the related literature is set as a model specification. These properties are specified in Temporal Trace Language (TTL).

\section{A. Mathematical Verification}

For the mathematical verification, equillibria analysis is used to describe situations in models where the values (continuous) approach a limit under certain conditions and stabilize. One important note that an equillibria condition(s) considered stable if the model always returns to its original position after small disturbances. To obtain possible equilibrium values for the other variables, first the temporal equations described in a differential equation form.

$$
\begin{aligned}
& \frac{d D f(t)}{d t}=\lambda \cdot[N g(t)-D f(t)] \cdot(1-D f(t)) \cdot(D f(t)) \\
& \left.\frac{d C a(t)}{d t}=\zeta \cdot[P c(t)-C a(t)] \cdot(1-C a(t)) \cdot \operatorname{Ca}(t)\right) \\
& \left.\frac{d C r(t)}{d t}=\varphi \cdot[\operatorname{Ar}(t)-\operatorname{Cr}(t)] \cdot(1-\operatorname{Cr}(t)) \cdot \operatorname{Cr}(t)\right)
\end{aligned}
$$

Assuming the parameters $\varphi, \zeta, \lambda$, are nonzero, from the equations 17 to 19 , the following cases can be distinguished.

$$
\begin{aligned}
& * N g(t)-D f(t)] \cdot(1-D f(t)) \cdot(D f(t))=0 \\
& [P c(t)-C a(t)] \cdot(1-C a(t)) \cdot C a(t))=0 \\
& [A r(t)-C r(t)] \cdot(1-C r(t)) \cdot C r(t))=0
\end{aligned}
$$

Later these are distinguished into cases.

$$
\begin{aligned}
& (* N g=D f) \vee(D f=1) \vee(D f=0) \\
& (P c=C a) \vee(C a=1) \vee(C a=0) \\
& (A r=C r) \vee(C r=1) \vee(C r=0)
\end{aligned}
$$

From here, the first set of conclusions can be derived where the equilibrium can only occur when $* N g=D f, D f=1$, or $D f=0$. By combining these three conditions, it implies it being re-written into a set of relationship in $(A \vee B) \wedge(D \vee$ E) expression:

$$
\begin{aligned}
& ((* N g=D f) \vee(D f=1) \vee(D f=0)) \wedge \\
& ((P c=C a) \vee(C a=1) \vee(C a=0)) \wedge \\
& ((A r=C r) \vee(C r=1) \vee(C r=0))
\end{aligned}
$$

This expression can be elaborated using the law of distributivity as $(A \wedge D) \vee(A \wedge E) \vee, . . \vee(C \wedge F)$.

$$
\begin{gathered}
(* N g=D f \wedge P c=C a \wedge A r=C r) \vee(* N g=D f \wedge C a=1 \wedge \\
C r=1) \vee \quad(D f=0 \wedge C a=0 \wedge C r=0)
\end{gathered}
$$

Table 2 provides a summarization of these equilibria. 
TABLE II

EQUILIBRIA STATES

\begin{tabular}{|c|c|}
\hline Concept & Equilibrium Equations \\
\hline$* O f$ & $* O f(\mathrm{t})=\beta \cdot C a(\mathrm{t})+\left[\left(1-\beta_{f}\right) \cdot O b(\mathrm{t})\right]$ \\
\hline$* T g$ & ${ }^{*} T g(\mathrm{t})=\mu . * F c(\mathrm{t})+\left[(1-\mu) \cdot{ }^{*} R d(\mathrm{t})\right]$ \\
\hline$* R d$ & $* R d(\mathrm{t})=P b(\mathrm{t}) \cdot\left[\overline{\mathrm{w}} \cdot C a(\mathrm{t})+(1-\overline{\mathrm{w}}) \cdot{ }^{*} O f(\mathrm{t})\right]$ \\
\hline$* \operatorname{Pr}$ & $* \operatorname{Pr}(t)=[1-\mathrm{Rd}(\mathrm{t})] \cdot[\operatorname{SSb}(t)] *[1-\rho * C g(t)+(1-\rho) * P b(t))]$ \\
\hline$* N g$ & ${ }^{*} N g(\mathrm{t})=\psi \cdot \operatorname{Pr}(\mathrm{t})+[(1-\psi) \cdot \operatorname{Se}(\mathrm{t})][1-\operatorname{Tg}(\mathrm{t})]$ \\
\hline$S b$ & $S b=B a \cdot[1-(1-A r)]$ \\
\hline $\mathrm{Se}$ & $\mathrm{Se}=P b \cdot[1-\mathrm{Ng}]$ \\
\hline$C g$ & $C g=\mathrm{w}_{\mathrm{c} 1} . A b+\mathrm{w}_{\mathrm{c} 2} . S i+\mathrm{w}_{\mathrm{c} 3} \cdot M v$ \\
\hline$P b$ & $P b=\left[\mathrm{w}_{\mathrm{pb} 1} \cdot A c+\mathrm{w}_{\mathrm{pb} 2} \cdot M v+\mathrm{w}_{\mathrm{pb} 3} \cdot C g\right] \cdot(1-P r)$ \\
\hline$P c$ & $P c=\left[\mathrm{w}_{\mathrm{Pcl} 1} P a+\mathrm{w}_{\mathrm{Pc} 2} I c+\mathrm{w}_{\mathrm{Pc} 33} S e\right] .(1-A r)$ \\
\hline$A r$ & $\left.A r=\left[\mathrm{w}_{\mathrm{ar} 1} \cdot D f+\mathrm{w}_{\mathrm{ar} 2} \cdot H r+\mathrm{w}_{\mathrm{ar} 3} \cdot P a\right)\right] \cdot(1-P c)$ \\
\hline$M v$ & $M v=\sigma\left(\mathrm{w}_{\mathrm{m} 1} . A b+\mathrm{w}_{\mathrm{m} 2} . S i+\mathrm{w}_{\mathrm{m} 3} . C g\right)+(1-\sigma)(A c)$ \\
\hline$A c$ & $A c=[\gamma \cdot B k+(1-\gamma) \cdot B f][1-N g]$ \\
\hline$D c$ & $D c=B f .[\eta \cdot M v+(1-\eta) \cdot P b]$ \\
\hline Ic & $I c=D c .[v \cdot S e+(1-v) \cdot B a]$ \\
\hline $\mathrm{Hr}$ & $H r=\phi \cdot D f+[(1-\phi) \cdot N g]$ \\
\hline
\end{tabular}

This later provides possible combinations equillibria points to be further analysed. However due to the huge amount of possible combinations, (in this case, $3^{3}=27$ possibilities), it makes it hard to come up with a complete classification of equilibria. However, for some typical cases, the analysis pursue further in case 1 to 3 , which depicts the equillibria of selected model cases.

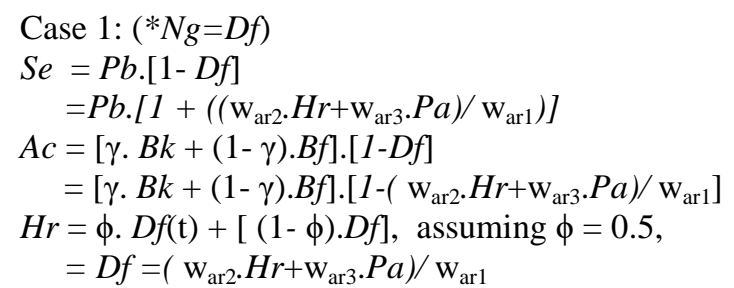

Case 2: $(D f=1)$

$\left.A r=\left[\mathrm{w}_{\mathrm{ar} 1}+\mathrm{w}_{\mathrm{ar} 2} \cdot H r+\mathrm{w}_{\mathrm{ar} 3} \cdot P a\right)\right] \cdot(1-P c)$ $=\left[\mathrm{w}_{\mathrm{ar} 1}+\mathrm{w}_{\mathrm{ar} 2} \cdot(\psi \cdot P r+[(1-\psi) \cdot S e])\right.$ $\left.\left.+\mathrm{w}_{\mathrm{ar} 3} \cdot P a\right)\right] \cdot(1-P c)$

$H r=\phi+[(1-\phi) . * N g]$, assuming $\phi=0$, $=* N g=\psi \cdot \operatorname{Pr}+[(1-\psi) \cdot S e]$

Case 3: $(P c=C a)$

$A r=\left[\mathrm{w}_{\mathrm{ar} 1} \cdot D f+\mathrm{w}_{\mathrm{ar} 2} \cdot H r+\mathrm{w}_{\mathrm{ar} 3} \cdot P a\right] \cdot(1-C a)$

$=\left[\mathrm{w}_{\mathrm{ar} 1} .\left(\mathrm{w}_{\mathrm{ar} 2} \cdot H r+\mathrm{w}_{\mathrm{ar} 3} \cdot P a\right) / \mathrm{w}_{\mathrm{ar} 1}+\mathrm{w}_{\mathrm{ar} 2} \cdot \phi\right.$. $\left.\left.\mathrm{w}_{\mathrm{ar} 2} \cdot H r+\mathrm{w}_{\mathrm{ar} 3} \cdot P a\right) / \mathrm{w}_{\mathrm{ar} 1}+((1-\phi) \cdot N g)+\mathrm{w}_{\mathrm{ar} 3} \cdot P a\right] \cdot(1-\mathrm{Ca})$

All of these equillibria conditions are obtain in the paper simulation results.

\section{B. Automated Verification}

On the other hand, this subsection deals with the verification of relevant dynamic properties of the cases considered in the human agent model, which is consistent with the literature. A state for a given Ontology Ont is an assignment of truth-values \{truth, false to the set of ground atoms $\mathrm{At}(\mathrm{Ont})$. The set of all possible states for an ontology Ont is denoted by STATES(Ont). Therefore, STATES(InteractionOnt) is the set of all interaction states. The standard satisfaction relation $\mid=$ between states and state properties is used $S \mid=P$ means that property $P$ holds in state $S$. Here, $\mid=$ is a predicate symbol in the language, usually used in infix notation, which is comparable to Holdspredicate in Situation Calculus, a logic formalism designed for representing and reasoning about dynamical domains [37]. In addition to this, a fixed time $T$ assumed which is linearly ordered. Therefore, a trace $\gamma$ over an ontology Ont and time frame $T$ is a time-indexed set of states can be formalized as, $\gamma_{t}(t \in T)$ in STATES(Ont) in a mapping;

$$
\gamma: T \rightarrow \operatorname{STATES}(\mathrm{Ont})
$$

This relationship can be presented as a $\operatorname{state}(\gamma, \mathrm{t}$, $\operatorname{output}(R)) \mid=\mathrm{p}$, means that state property $\mathrm{p}$ is true at the output of role $R$ in the state of trace $\gamma$ at time point t [38]. In this paper, these kinds of atoms referred as holds atoms. Based on such Holds atoms the dynamic properties (from the differential equations) built using the basic logical connectives and quantification. VP1 to VP3 present these properties, which are in both semi-formal and informal representations.

- VP1: Low in Social Influence Will Increase Refusal Behaviour

Individuals with low social influence tend to develop high chance in refusing to perform actions.

$\mathrm{VP} 1 \equiv \forall \gamma:$ TRACE $, \quad \forall \mathrm{t} 1, \quad \mathrm{t} 2: \mathrm{TIME}, \quad \forall \mathrm{F} 1, \mathrm{~F} 2, \mathrm{H} 1, \mathrm{H} 2$, d:REAL

$[\operatorname{state}(\gamma, \mathrm{t} 1) \mid=$ social_influence $(\mathrm{F} 1) \&$

$\operatorname{state}(\gamma, \mathrm{t} 1) \mid=$ consistency_refusal_action $(\mathrm{H} 1) \&$

$\operatorname{state}(\gamma, \mathrm{t} 2) \mid=$ social_influence $(\mathrm{F} 2) \&$

state $(\gamma, \mathrm{t} 2) \mid=$ consistency_refusal_action $(\mathrm{H} 2) \&$

$\mathrm{t} 2 \geq \mathrm{t} 1+\mathrm{d} \& \mathrm{~F} 1<0.3 \& \mathrm{~F} 1>\mathrm{F} 2] \Rightarrow \mathrm{H} 2>\mathrm{H} 1$

This property reflects that when there is a lack of social support or collaboration, then the possibility of achieving target behaviour by the agent will be high. The attribution depicts that with adequate supports, the agent likelihood of achieving the target-predefined objective is high. This property is consistent with previous studies [39], [40], [41] where it was discovered that the collaboration and teamwork aid and increase individual target accomplishment within the same environment.

- VP2: Low in Planned Action Will Increase Refusal Behaviour

Individuals with low planned action tend to develop high chance in refusing to perform actions.

$\mathrm{VP} 2 \equiv \forall \gamma:$ TRACE, $\forall \mathrm{t} 1$, t2:TIME, $\forall \mathrm{F} 1, \mathrm{~F} 2, \mathrm{H} 1, \mathrm{H} 2$, $\mathrm{d}:$ REAL

$[\operatorname{state}(\gamma, \mathrm{t} 1) \mid=$ planned_action $(\mathrm{F} 1) \&$

$\operatorname{state}(\gamma, \mathrm{t} 1) \mid=$ consistency_refusal_action $(\mathrm{H} 1) \&$

$\operatorname{state}(\gamma, \mathrm{t} 2) \mid=$ planned_action $(\mathrm{F} 2) \&$

$\operatorname{state}(\gamma, \mathrm{t} 2) \mid=$ consistency_refusal_action $(\mathrm{H} 2) \&$

$\mathrm{t} 2 \geq \mathrm{t} 1+\mathrm{d} \& \mathrm{~F} 1<0.3 \& \mathrm{~F} 1>\mathrm{F} 2] \Rightarrow \mathrm{H} 2>\mathrm{H} 1$

In this property, low in planned action will result to increase in behaviour refusal. The property reflects that when there is a lack of planning by an agent then the likelihood of achieving target behaviour by the agent will be low. This property finding is evidence in some previous studies [42], [43], [44] where it was discovered agents' 
planning has direct implication on the successfulness of an action.

- VP3: Trigger Will Improve Negative Thoughts

Individuals with high trigger tend to develop lesser chance of having negative thoughts.

$$
\begin{aligned}
& \text { VP3 } \equiv \forall \gamma: \text { TRACE, } \forall \mathrm{t} 1, \mathrm{t} 2: \mathrm{TIME}, \forall \mathrm{F} 1, \mathrm{H} 1, \mathrm{M} 1, \mathrm{~d}: \mathrm{REAL} \\
& \text { [state }(\gamma, \mathrm{t} 1) \mid=\operatorname{trigger}(\mathrm{v} 1) \& \\
& \operatorname{state}(\gamma, \mathrm{t} 1) \mid=\text { level_negative_thoughts }(\mathrm{w} 1) \& \\
& \operatorname{state}(\gamma, \mathrm{t} 2) \mid=\text { personal_trigger }(\mathrm{v} 2) \& \\
& \text { v2 }>\mathrm{v} 1] \Rightarrow \exists \mathrm{t} 3: \mathrm{TIME}>\mathrm{t} 2: \mathrm{TIME} \& \\
& \text { t2:TIME > t1:TIME [ }>\operatorname{state}(\gamma, \quad \mathrm{t} 3) \mid= \\
& \text { level_negative_thoughts }(\mathrm{w} 2) \& \mathrm{w} 1>\mathrm{w} 2]
\end{aligned}
$$

The property illustrates that precise and timely trigger will improve negative thought and reduce the threat. The finding of this property is similar to previous studies [4], [45], [46], [47] results, which pointed out that trigger factor is vital in the reduction of negative thoughts in order to obtain an achievable action.

\section{CONCLUSION}

This study has been able to explore formal analysis of behavioural change process model as presented earlier in Fogg's study [3]. The model depicts the reduction of reactance related to behavioural change based on personal characteristics for successful interventions. Next, based on the simulated results, a mathematical analysis performed to demonstrate the occurrence of equilibrium conditions, which depicts the convergence, and stability of the model. To prove the relations, simulations conducted and results verified based on several properties using mathematical analysis and automated verification. It concluded that the proposed model provides a basic building block in designing a software agent that will support successful human interventions.

\section{REFERENCES}

[1] C. Abraham and S. Michie. A taxonomy of behaviour change techniques used in interventions. Health psychology, 2008. 27(3), 379.

[2] W. Hardeman, M. Johnston, D. Johnston, D. Bonetti, N. Wareham and A.L Kinmonth. Application of the Theory of Planned Behaviour in Behaviour Change Interventions: A Systematic Review. Psychology and Health, 2002. 17(2), 123-158.

[3] B. J. Fogg. A behaviour model for persuasive design. Proceedings of the 4th International Conference on Persuasive Technology, 2009.

[4] M. Klein, N. Mogles and A. Wissen. Why won't you do what's good for you? Using intelligent support for behavior change. Human Behavior Unterstanding, 2011. 104-115.

[5] E. Andre, E. Bevacqua, D. Heylen, R. Niewiadomski, C. Pelachaud, C. Peters and I. Poggi. Non-verbal persuasion and communication in an affective agent. Emotion-Oriented Systems, 2011. 585-608.

[6] N. Murtagh, B. Gatersleben and D. Uzzell. Identity threat and resistance to change: evidence and implications from transport-related behaviour. Identity Process Theory: Identity, Social Action and Social Change, 2014. 32(4), 335.
[7] R. Folger, D.B. Ganegoda, D.B. Rice, R. Taylor and D.X. Wo. Bounded autonomy and behavioural ethics: Deonance and reactance as competing motives. Human Relations, 2013. 66(7), 905-924.

[8] S.A. Rains. The Nature of Psychological Reactance Revisited: A Meta-Analytic Review. Human Communication Research, 2013. 39(1), 47-73.

[9] S.M. Edwards, H. Li, and J.H. Lee. Forced exposure and psychological reactance: Antecedents and consequences of the perceived intrusiveness of pop-up ads. Journal of Advertising, 2002. 31(3), 83-95.

[10] B.L Quick and M.T. Stephenson. Further evidence that psychological reactance can be modeled as a combination of anger and negative cognitions. Communication Research, 2007. 34(3), 255-276.

[11] B.L Quick and M.T. Stephenson. Examining the role of trait reactance and sensation seeking on perceived threat, state reactance, and reactance restoration. Human Communication Research, 2008. 34(3), 448-476.

[12] J.P Dillard and L. Shen. On the nature of reactance and its role in persuasive health communication. Communication Monographs, 2005. 72(2), 144-168.

[13] H.C. Sinclair, D. Felmlee, S. Sprecher and B.L. Wright. Don't Tell Me Who I Can't Love A Multimethod Investigation of Social Network and Reactance Effects on Romantic Relationships. Social Psychology Quarterly. 2015. 78(1), 77-99

[14] J. Greenberg. Understanding Psychological Reactance. Zeitschrift für Psychologie, 2015. 223(4), 205-214.

[15] R. Borland, H.H. Yong, N. Wilson, G.T. Fong, D. Hammond, K.M. Cummings and A. McNeill. How reactions to cigarette packet health warnings influence quitting: Findings from the ITC Four-Country survey. Addiction, 2009. 104(4), 669-675.

[16] J.D Ford, L.W. Ford and A. D'Amelio. Resistance to change: The rest of the story. Academy of Management Review, 2008. 33(2), 362-377.

[17] K.A. Matthews. Psychological perspectives on the type A behaviour pattern. Psychological bulletin, 1982. 91(2), 293.

[18] M.A Clee and R.A. Wicklund. Consumer behaviour and psychological reactance. Journal of Consumer Research, 1980. 389-405.

[19] R.L Miller. Mere exposure, psychological reactance and attitude change. Public Opinion Quarterly, 1976. 40(2), 229233

[20] S.J. Leal, M. Napoletano, A. Roventini and G. Fagiolo. Rock Around The Clock: An Agent-Based Model of Low-And High-Frequency Trading. Journal of Evolutionary Economics. 2016. 26(1):49-76.

[21] H. Mohammed, A. Aziz, N. ChePa, A.H.M. Shabli, J.A.A. Bakar and A. Alwi. A computational agent model for stress reaction in natural disaster victims. In Information Science and Applications (ICISA). 2016 (pp. 817-827). Springer Singapore.

[22] A. Malawska. Topping CJ. Evaluating the Role Of Behavioural Factors and Practical Constraints In the Performance of an Agent-Based Model of Farmer Decision Making. Agricultural Systems. 2016. 143:136-46.

[23] T. Matteis, G. Liedtke and W. Wisetjindawat. A Framework for Incorporating Market Interactions in an Agent-Based Model for Freight Transport. Transportation Research Procedia. 2016. 12:925-37.

[24] A. Ojeniyi, A. Aziz and Y. Yusof. Designing A BDI Agent Reactant Model of Behavioral Change Intervention, Jurnal Teknologi. 2015. 78(2-2). 
[25] C.S.K. Hendershot, W.H. Witkiewitz, G.A. George and A. Marlatt. Relapse Prevention for Addictive Behaviours. Substance Abuse Treatment, Prevention, and Policy. 2011. 6(1): 17.

[26] J.O. Prochaska, C.A. Butterworth V. Redding, N. Burden, M. Perrin, M. Leo and J.M. Flaherty-Robb. Initial Efficacy Of MI, TTM Tailoring And HRI's With Multiple Behaviors For Employee Health Promotion. 2009. 46(3): 226-31.

[27] A. Bandura. Self-efficacy: Toward A Unifying Theory of Behavioral Change. Psycho-logical Review. 1977. 84(2): 191-215.

[28] D. Dubois, D.D. Rucker and R.E. Petty. Internal versus External Informational Sources: Causes and Consequences for Attitude Certainty and Attitude-Behaviour Consistency. Advances in Consumer Research. 2010. 37.

[29] J.L. Hale. The Theory of Reasoned Action. The Persuasion Handbook: Developments in Theory and Practice. 2002. 259-286.

[30] D.E. Montano and D. Kasprzyk. Theory of Reasoned Action, Theory of Planned Behaviour, And The Integrated Behavioural Model. Health Behaviour and Health Education: Theory, Research, and Practice. 2008. 4: 67-95

[31] E.J. Henshaw and C.R. Freedman-Doan. Conceptualizing Mental Health Care Utilization Using The Health Belief Model. Clinical Psychology: Science and Practice. 2009. 16(4): 420-439.

[32] R. Gifford. The dragons of inaction: Psychological barriers that limit climate change mitigation and adaptation. American Psychologist, 2011. 66(4), 290

[33] M. Klein, N. Mogles and A. van Wissen. An intelligent coaching system for therapy adherence. Pervasive Computing, IEEE, 2013. 12(3), 22-30.

[34] L.M. Ritterband, F.P. Thorndike, D.J. Cox, B.P. Kovatchev and L.A. Gonder-Frederick. A behavior change model for internet interventions. Annals of Behavioral Medicine, 2009. 38(1), 18-27.

[35] Ojeniyi, A., Ab Aziz, A., \& Yusof, Y. (2015, August). Verification analysis of an agent based model in behaviour change process. In Agents, Multi-Agent Systems and Robotics (ISAMSR), 2015 International Symposium on (pp. 87-92). IEEE.

[36] T. Bosse, C.M. Jonker, L. Meij, A. Sharpanskykh and J. Treur. Specification and Verification of Dynamics in Agent Models. International Journal of Cooperative Information Systems, 2009. 18, pp. 167-193.
[37] W.T. Bickmore and R. Picard. Establishing and Maintaining Long-Term Human-Computer Relationships. Transactions on Computer-Human Interaction. 2004.

[38] T. Bosse, C.M. Jonker, L. Meij and J. Treur. A Language and Environment for Analysis of Dynamics by Simulation. International Journal of Artificial Intelligence Tools, 2007. vol. 16, pp. 435-464.

[39] S. Garg, S. Srinivasan and V. Jaglan. Multi-agent Collaboration Engine for Supply Chain Management. International Journal of Computer Science and Engineering, 2011. 3(7), 2765-2773.

[40] L. Zheng. AMD based Service Agent Collaboration and Specification. In High-Performance Computing and Communications \& 2013 IEEE International Conference on Embedded and Ubiquitous Computing (HPCC_EUC), 2013 IEEE 10th International Conference (pp. 2277-2284). IEEE.

[41] S.D. Ramchurn, F. Wu, W. Jiang, J.E. Fischer, S. Reece and S. Roberts, N.R. Jennings. Human-agent collaboration for disaster response. Autonomous Agents and Multi-Agent Systems. 2015. 1-30.

[42] H.A. Oinas-Kukkonen. A Foundation for the Study of Behaviour Change Support Systems. Personal and Ubiquitous Computing. 2013. 17(6), 1223-1235.

[43] S. Michie, M. Johnston, J. Francis, W. Hardeman and M. Eccles. From Theory to Intervention: Mapping Theoretically Derived Behavioural Determinants to Behaviour Change Techniques. Applied Psychology. 2008. 57(4), 660-680. doi:10.1111/j.1464-0597.2008.00341.x

[44] A. Hyland, C. Higbee, R. Borland, M. Travers, G. Hastings, G.T. Fong and K.M. Cummings. Attitudes and Beliefs about Second-hand Smoke and Smoke-Free Policies in Four Countries: Findings from the International Tobacco Control Four Country Survey,Nicotine \& Tobacco Research. 2009. 11(6), 642-649.

[45] E. Palumbo. The Influence of Positive and Negative Death Attitudes on Medical Students' Empathy and Attitudes toward End-of-Life Care. 2015.

[46] J. Aronson, D. Burgess, S.M. Phelan and L. Juarez. Unhealthy Interactions: The Role of Stereotype Threat in Health Disparities. American Journal of Public Health. 2013. 103(1), 50-56.

[47] T. Schmader and S.L. Beilock. An Integration of Processes That Underlie Stereotype Threat. Stereotype Threat: Theory, Process, and Application. 2012. 34-50. 